\title{
Storms before the calm
}

A bout a year ago, a resident paged to say: "The family of 'Mr. Q' wants to know if you think he should be intubated." Mr. Q had gone to sea at the age of nine, to catch lobsters with his father. In later life he had been a woodsman and a meat cutter. His last 30 working years were spent keeping naval weaponry in tip-top condition. During WWII, he had survived, against some odds, a tuberculous empyema leaving him with a pleural space half full of calcium and restrictive pulmonary function. A long smoking history and moderate chronic obstructive pulmonary disease added to the medical challenge. Quite how extensive a challenge didn't become obvious until well beyond my deceptively simple response to the resident: "Why wouldn't we give him a chance." After all, he had recently walked independently into the clinic and had never needed emergency visits or admissions. Another challenge, also not obvious early on, was how to provide quality care for Mr. Q within constraints of responsible resource allocation. As often happens, no amount of policy, institutional planning, logical analysis, let alone traditional concepts of advance care planning, can determine what course individual care will take for the Mr. Qs we will meet from time to time.

It took weeks to liberate him from mechanical ventilation. A new swallowing difficulty doomed him days later to the first of several episodes of minor aspiration. "Minor" in all aspects save outcome - for him and for us. Well-intentioned, well-reasoned, welldocumented goals of care, clearly indicating "no heroics," didn't fly when Mr. Q's competent response in a crisis was: "I don't want that stuff, but if it's a matter of life or death. ..."

He survived several subsequent crises and continued to firmly refuse any technically assisted feeding. His aim was to go home - and eat; he wasn't interested in half measures that bypassed his taste buds. That's how the first months played out: the intensive care unit in a crisis followed by the

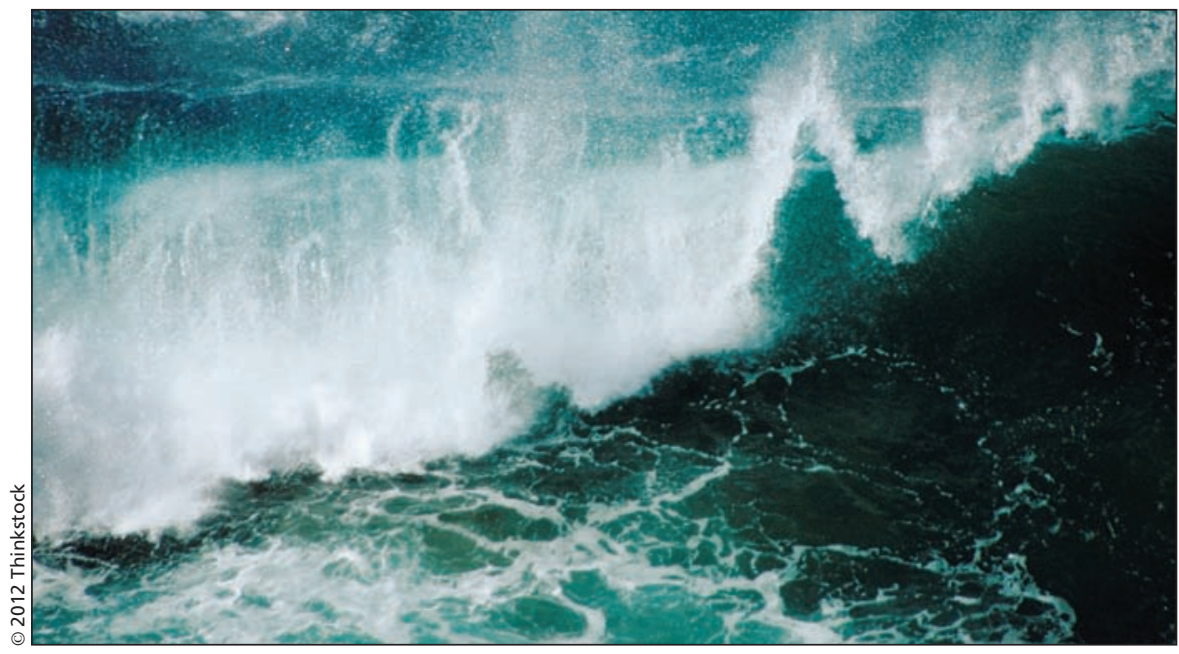

"step-down" unit. He'd go days with the tracheostomy "corked" and then crash, sometimes slowly, sometimes faster and for longer. Each time he would come through, get beyond some short-term delirium, and settle down again.

With a Passy-Muir valve he could talk, but he didn't like his nasogastric tube. Liquid feeds weren't "food." Nevertheless, he was on the right side of the grass as he preferred to be, not so much for himself, but because of a strong belief that his family needed him. He cared for his family as the patriarch and in turn was loved and cared for by his extensive family who made it very clear they would never make a decision for him if he proved unable. His was the choice to carry on or to give up the fight — and fight he did.

I could not have foreseen that my deceptively straightforward answer to the intubation question would be the first step along this obstacle-strewn path. Day-by-day, episode-by-episode, this uncertain path defined a man's life, and his preferred approach to care, as we charted our way through new storms. We came through, on our part, despite occasional dissension and discomfort, even some guilt, forgetting perhaps that as survivors of previous life-and-death crises, the Mr. Qs of this world may see the only option as living to the very last breath, no matter how tortured that course appears to others.
After many repetitions of the cycle, both he and his family agreed to a percutaneous endoscopic gastrostomy. He restarted the journey toward his goal of independence. He used a stationary bicycle to maintain strength in his legs. He'd cruise around the unit with a walker, oxygen tank and respiratory therapist in tow. He came off the ventilator again, but just during the day. He "simply" needed a few hours of assisted ventilation at night to keep him on the straight and narrow.

Many months ago, he went home for the first in a series of short visits, undoubtedly chatting up a storm and delighting in reacquainting with his cats. If he could walk to his boat, he'd be out to sea in a minute. He is, in all ways, a survivor. The family photographs on his wall and a special blanket on his bed are outward reminders of home and the values that keep him going. He maintains what independence he can, eschews the "remote" and manages the TV controls with the packaging of a long surgical instrument. Life suffices and he is content.

\section{Graeme M. Rocker MD}

Professor of medicine

Dalhousie University

Halifax, NS

This is a true story. "Mr. Q" has given his written consent for this story to be told. 